\title{
Association of Demographic Characteristics and Utilization of Cervical Cancer Screening Services among Women in Ikwerre, Southern Nigeria
}

\author{
Okachi-Ordu, C. ${ }^{1}$, Nworuh, O.B. ${ }^{2}$, Nwaokoro, J.C. ${ }^{3}$, Ibe, S.N.O. ${ }^{4}$ \\ ${ }^{1-4}$ Department of Public Health, Federal University of Technology, Owerri, Nigeria. \\ Corresponding Author: Okachi-Ordu, C.
}

DOI: https://doi.org/10.52403/ijrr.20220253

\begin{abstract}
Cervical cancer is the leading cause of cancer deaths among women in developing countries. This was a cross-sectional descriptive study carried out to investigate the utilization of cervical cancer screening services among women in Ikwerre, Southern Nigeria. The multi stage sampling technique was used to select 399 women between the ages of 21 and 65years for this study. A well-structured questionnaire after being validated and tested for reliability was administered to the participants. An informed consent was also obtained from all the participants in this study. Chi-square was used to test the relationship between variables at $\mathrm{p} \leq \mathbf{0 . 0 5}$ significant level. Results showed that demographic characteristics found to be associated with utilization of cervical cancer screening services in this study were age $12(12.4 \%)$ at $\mathrm{P}=0.001$, marital status $14(9.5 \%)$ at $\mathrm{P}=0.002$, education $19(9.0 \%)$ at $\mathrm{P}=0.001$, number of children $14(6.8 \%)$ at $\mathrm{P}=0.009$ and income level $19(45.2 \%)$ at $\mathrm{P}=0.001$. From the findings of this study, utilization of cervical cancer screening services among women in Ikwerre was abysmally low. It was recommended that medical personnel play a major role in enlightening the public on the importance of cervical cancer screening and availability of the screening services. The government should also ensure that the cost of the screening service was made affordable.
\end{abstract}

Keywords: Cervical cancer, Screening, Demography, Utilization

\section{INTRODUCTION}

Cancer of the cervix is currently the commonest cancer and the leading cause of cancer deaths among women in developing countries. ${ }^{[1]}$ It is also the second most common cancer among women worldwide. In 2008 alone, not less than 530,000 new cases of the disease and 275,000 deaths were recorded globally. Out of this number, $90 \%$ of the deaths were recorded in the developing countries. In the WHO African region, about 75,000 new cases were recorded for the same year. ${ }^{[1]}$ Cervical cancer is the second commonest cancer in Nigerian women and the leading gynecological malignancy with high mortality among the afflicted. In Nigeria, an estimated 10,000 new cases of cervical cancer and 8000 deaths due to the disease are recorded among women yearly. [2] Moreover, Nigeria has an estimated fiveyear prevalence of $21.6 \%$ for cervical cancer. ${ }^{[3]}$ In 2012, 5\% was reported as the prevalence of cervical cancer among women in Ilorin, Nigeria. ${ }^{[4]}$ However, a study in 2010 showed that cancer of the cervix accounted for $63 \%$ of all gynaecological cancers seen in the Obstetrics and Gynaecology Department of the University of Ilorin Teaching Hospital, Ilorin, Nigeria. [5]

Papanicolaou (Pap) smear cytology screening method to identify precancerous lesions has helped in achieving massive reduction in the burden of cancer of the 
cervix especially in the developed countries. ${ }^{[6]}$ Other less invasive techniques have been developed for rapid screening of cancer of the cervix. Such techniques include Visual Inspection with Acetic Acid (VIA) and Visual Inspection with Lugol's Iodine (VILI). They have been discovered to be less sensitive compared to cytologic examination through Pap smear. ${ }^{[6]}$ Due to the increasing burden of cancers generally, the World Health Assembly (WHA), adopted resolution 58.22 which urged member states to intensify action against cancer through creation of National Cancer Control Programme. [1] In Nigeria, the National Cancer Control Programme was developed in 2008 with the view of reducing the morbidity and mortality associated with cancer and its socioeconomic impacts. Within the framework of the National Cancer Control Plan, the Federal Ministry of Health, Nigeria ${ }^{[7]}$ established a cervical cancer control plan. The plan adopted screening for early disease detection of cervical cancer and human papilloma virus (HPV) vaccination for primary prevention in girls of $9-15$ years.

Although screening is a known cost effective strategy used in reducing the burden of cervical cancer worldwide, its uptake particularly in developing countries is still abysmal. ${ }^{[8]}$ One of the barriers to access is that most cervical cancer screening services (provided by governmental and non-governmental agencies) in Nigeria had been poorly coordinated. Most services are urban-based; the rural and semi-urban dwellers are often neglected. Another problem is low awareness of women about cancer of the cervix and cervical cancer screening. In Rivers State, Nigeria, screening services are mostly found in government owned tertiary and secondary health facilities with assistants from few non-governmental organizations. The cost of screening could be as high as five thousand naira in such facilities. In a country such as Nigeria, with a timid population of people living below the poverty line and with a healthcare system that is predominantly dependent on out-ofpocket expenditure, such cost of service could be prohibitive. However, cytological screening using Pap smear seems to be the preferred method of screening in these facilities. ${ }^{[9]}$

In spite of efforts from governmental and nongovernmental organizations to improve access to cervical cancer screening services in Nigeria, uptake has been appalling. Several factors are associated with uptake of cervical screening tests worldwide. Such factors include age of the women, their marital status, parity, risk perception, financial constraint, and knowing someone who has cancer of the cervix. ${ }^{[10]}$ However, works on the level of participation and utilization of cervical cancer screening services and the influence of socio-demographic factors on utilization rate are limited. It is on this premise that a research of this nature was proposed.

\section{MATERIALS AND METHODS}

This study was a cross-sectional descriptive study carried out at Ikwerre Local Government Area, Rivers State, Southern Nigeria. The multi-stage sampling technique was used to select participants for the study. An informed consent was obtained from all the participants in the study. A well-structured questionnaire was administered to the participants who were women between the ages of 21-65 years.

\section{Statistical Methods}

The data obtained from the study was uploaded into the Statistical Package for Social Sciences (SPSS) version 21 software. The statistical association between women's dependent variables and independent variables was tested using chisquare at 0.05 level of significance.

\section{RESULTS}

A total of 399 women participated in this study. Table 1 represents the demographic characteristics among the study group. The largest number of the participants $(250 ; 62.7 \%)$ falls within the age of 21-35 years, followed by the 36-45 
with $97(24.3 \%)$. More than half of the respondents $217(54.4 \%)$ were married, 148 $(37.1 \%)$ were singles and $20(5 \%)$ were widowed. Similarly more than half, 212 $(53.1 \%)$ attained up to tertiary education, $102(25.6 \%)$ had secondary education and $40(10 \%)$ had primary education. A total of $134(33.6 \%)$ were civil servants, 116 $(29.1 \%)$ were students and $113(28.3 \%)$ were involved in trading. The respondents were predominantly Christians (383; $96.0 \%), 15(3.8 \%)$ and $1(0.3 \%)$ were Islam and African traditional religion respectively. Those who had 1-3 children were 35 (8.8\%), $76(19.1 \%)$ had 4-6 children while $207(51.9 \%)$ were yet to have children. The largest group of the income earners were those earning below 30,000 Naira with 229 (57.4\%), followed by those earning 31,000 40,000 Naira at 100 (25.1\%). Only 42 $(10.5 \%)$ earned above 60,000 Naira. On Table 2, while some of the reasons for nonutilization of cervical cancer screening services among the women studied include non-availability at the health facility (26; $6.8 \%)$, attitude of health workers (11; $2.9 \%)$, cost of the screening test $(4 ; 1.1 \%)$ and time spent at health facility $(2,0.5 \%)$; apparently most of the women do not have clear or justifiable reasons for nonutilization of cervical cancer screening services.

The association of demographic characteristics and utilization of cervical cancer screening services was shown on Table 3. Significant demographic characteristics found to be associated with utilization of cervical cancer screening services in this study include age $(\mathrm{p}=0.001$, LR $\left.\chi^{2}=16.3\right)$, marital status $(\mathrm{p}=0.002, \mathrm{LR}$ $\left.\chi^{2}=12.5\right)$, education $\left(\mathrm{p}=0.001\right.$, LR $\chi^{2}=$ $24.9)$, number of children $\left(\mathrm{p}=0.009\right.$, LR $\chi^{2}=$ 13.4), and income level ( $\mathrm{p}=0.001$, LR $\chi^{2}=$ 94.9). Among the respondents aged 21-35 years, only $7(2.8 \%)$ utilized cervical cancer services; and for the 36-45 years, 12 $(12.4 \%)$ utilized the services. None of the women who were above 45 years old utilized the screening services. Among the few women that utilized the services were the singles and married women. Up to 14 $(9.5 \%)$ of single women and $5(2.3 \%)$ of married ones utilized the services while none of the divorced and widowed utilized the services. Education showed inverse impart in the utilization of cervical cancer screening services in the study area. Only those without formal education were noticed to be utilizing the services. $11.5 \%$ of traders utilized the service, $4.5 \%$ of civil servants while no other occupation was indicated to have utilized the services. Though religion was not found as a significant factor for cervical cancer screening utilization in this study, the only women that responded that they utilized the services were all Christians. Up to $6.8 \%$ of women who do not have kids do utilize the services compared to $6.6 \%$ for those that had up to 4 -6 children and "zero" each for the 1-3 children, 5-8 children and more than ten children. On income status, only the respondents that earn more than 60,000 Naira (144 USD) monthly utilized the utilization of cervical cancer screening services.

Table 1: Demographic Characteristics of the Respondents

\begin{tabular}{|c|c|c|}
\hline Item & Demographic Class & $\begin{array}{l}\text { Total } \\
(n=399) \\
n(\%)\end{array}$ \\
\hline \multirow[t]{4}{*}{ Age } & 21-35 years & $250(62.7)$ \\
\hline & $36-45$ years & $97(24.3)$ \\
\hline & 46-55 years & $27(6.8)$ \\
\hline & 56-65 years & $25(6.3)$ \\
\hline \multirow[t]{4}{*}{ Marital Status } & Single & $148(37.1)$ \\
\hline & Married & $217(54.4)$ \\
\hline & Divorced & $14(3.5)$ \\
\hline & Widowed & $20(5.0)$ \\
\hline \multirow[t]{4}{*}{ Education } & Primary & $40(10.0)$ \\
\hline & Secondary & $102(25.6)$ \\
\hline & Tertiary & $212(53.1)$ \\
\hline & No formal education & $45(11.3)$ \\
\hline \multirow[t]{5}{*}{ Occupation } & Civil servant & $134(33.6)$ \\
\hline & Student & $116(29.1)$ \\
\hline & Trader & $113(28.3)$ \\
\hline & Farmer & $35(8.8)$ \\
\hline & House wife & $1(0.3)$ \\
\hline \multirow[t]{3}{*}{ Religion } & Christianity & $383(96.0)$ \\
\hline & Islam & $15(3.8)$ \\
\hline & African Traditional Religion & $1(0.3)$ \\
\hline \multirow{5}{*}{$\begin{array}{l}\text { Number of } \\
\text { children }\end{array}$} & $1-3$ & $35(8.8)$ \\
\hline & $4-6$ & $76(19.1)$ \\
\hline & $7-10$ & $55(13.8)$ \\
\hline & Greater than 10 & $26(6.5)$ \\
\hline & None & $207(51.9)$ \\
\hline \multirow{5}{*}{$\begin{array}{l}\text { Income in Naira } \\
\text { (A) }\end{array}$} & $<30,000$ & $229(57.4)$ \\
\hline & $31,000-40,000$ & $100(25.1)$ \\
\hline & $41,000-50,000$ & $16(4.0)$ \\
\hline & $51,000-60,000$ & $12(3.0)$ \\
\hline & Greater than 60,000 & $42(10.5)$ \\
\hline
\end{tabular}


Okachi-Ordu, C. et.al. Association of demographic characteristics and utilization of cervical cancer screening services among women in Ikwerre, Southern Nigeria.

Table 2: Reason for non-utilization of cervical cancer screening service

\begin{tabular}{|l|l|l|}
\hline Reason & n & \% \\
\hline Non availability at the health facility & 26 & 6.8 \\
\hline Cost of the screening test & 4 & 1.1 \\
\hline Attitude of health workers & 11 & 2.9 \\
\hline Time spent at health facility & 2 & 0.5 \\
\hline NO clear reason & 337 & 88.7 \\
\hline Total & 380 & 100.0 \\
\hline
\end{tabular}

Table 3: Association of demographic Characteristics and utilization of Cervical Cancer Screening Services

\begin{tabular}{|c|c|c|c|c|c|c|c|}
\hline \multirow[t]{2}{*}{ Item } & \multirow[t]{2}{*}{ Variable Class } & \multirow{2}{*}{$\begin{array}{l}\begin{array}{l}\text { Total } \\
(n=399)\end{array} \\
n(\%)\end{array}$} & \multicolumn{2}{|c|}{$\begin{array}{l}\text { Utilized } \\
(\mathrm{n}=19)\end{array}$} & \multicolumn{2}{|c|}{ Not Utilized $(n=380)$} & \multirow[t]{2}{*}{ p-value $\left(\operatorname{LR} \chi^{2}\right)$} \\
\hline & & & $\mathbf{n}$ & $(\%)$ & $\mathbf{n}$ & $(\%)$ & \\
\hline \multirow[t]{4}{*}{ Age } & 21-35 years & $250(62.7)$ & 7 & 2.8 & 243 & 97.2 & \multirow{4}{*}{$\begin{array}{l}0.001 \\
(16.307)\end{array}$} \\
\hline & $36-45$ years & $97(24.3)$ & 12 & 12.4 & 85 & 87.6 & \\
\hline & $46-55$ years & $27(6.8)$ & 0 & 0.0 & 27 & 100.0 & \\
\hline & $56-65$ years & $25(6.3)$ & 0 & 0.0 & 25 & 100.0 & \\
\hline \multirow[t]{4}{*}{ Marital Status } & Single & $148(37.1)$ & 14 & 9.5 & 134 & 90.5 & \multirow{4}{*}{$\begin{array}{l}0.002 \\
(12.524)\end{array}$} \\
\hline & Married & $217(54.4)$ & 5 & 2.3 & 212 & 97.7 & \\
\hline & Divorced & $14(3.5)$ & 0 & 0.0 & 14 & 100.0 & \\
\hline & Widowed & $20(5.0)$ & 0 & 0.0 & 20 & 100.0 & \\
\hline \multirow[t]{4}{*}{ Education } & Primary & $40(10.0)$ & 0 & 0.0 & 45 & 100.0 & \multirow{4}{*}{$\begin{array}{l}0.001 \\
(24.867)\end{array}$} \\
\hline & Secondary & $102(25.6)$ & 0 & 0.0 & 40 & 100.0 & \\
\hline & Tertiary & $212(53.1)$ & 0 & 0.0 & 102 & 100.0 & \\
\hline & No formal education & $45(11.3)$ & 19 & 9.0 & 193 & 91.0 & \\
\hline \multirow[t]{5}{*}{ Occupation } & Civil servant & $134(33.6)$ & 6 & 4.5 & 128 & 95.5 & \multirow{5}{*}{$\begin{array}{l}0.001 \\
(23.105)\end{array}$} \\
\hline & Student & $116(29.1)$ & 0 & 0.0 & 116 & 100.0 & \\
\hline & Trader & $113(28.3)$ & 13 & 11.5 & 100 & 88.5 & \\
\hline & Farmer & $35(8.8)$ & 0 & 0.0 & 35 & 100.0 & \\
\hline & House wife & $1(0.3)$ & 0 & 0.0 & 1 & 100.0 & \\
\hline \multirow[t]{3}{*}{ Religion } & Christianity & $383(96.0)$ & 19 & 5.0 & 364 & 95.0 & \multirow{3}{*}{$\begin{array}{l}0.451 \\
(1.594)\end{array}$} \\
\hline & Islam & $15(3.8)$ & 0 & 0.0 & 15 & 100.0 & \\
\hline & African Traditional Religion & $1(0.3)$ & 0 & 0.0 & 1 & 100.0 & \\
\hline \multirow[t]{5}{*}{ Number of children } & $1-3$ & $35(8.8)$ & 0 & 0.0 & 35 & 100.0 & \multirow{5}{*}{$\begin{array}{l}0.009 \\
(13.442)\end{array}$} \\
\hline & $4-6$ & $76(19.1)$ & 5 & 6.6 & 71 & 93.4 & \\
\hline & $7-10$ & $55(13.8)$ & 0 & 0.0 & 55 & 100.0 & \\
\hline & Greater than 10 & $26(6.5)$ & 0 & 0.0 & 26 & 100.0 & \\
\hline & None & $207(51.9)$ & 14 & 6.8 & 193 & 93.2 & \\
\hline \multirow[t]{5}{*}{ Income in Naira (N) per Month } & $<30,000$ & $229(57.4)$ & 0 & 0.0 & 229 & 100.0 & \multirow{5}{*}{$\begin{array}{l}0.001 \\
(94.93)\end{array}$} \\
\hline & $31,000-40,000$ & $100(25.1)$ & 0 & 0.0 & 100 & 100.0 & \\
\hline & $41,000-50,000$ & $16(4.0)$ & 0 & 0.0 & 16 & 100.0 & \\
\hline & $51,000-60,000$ & $12(3.0)$ & 0 & 0.0 & 12 & 100.0 & \\
\hline & $>60,000$ & $42(10.5)$ & 19 & 45.2 & 23 & 54.8 & \\
\hline
\end{tabular}

\section{DISCUSSION}

Utilization of cervical cancer screening services by women in Ikwerre, Southern Nigeria was quite poor $(4.8 \%)$ as majority of the women there do not utilize the services. Similar poor utilization was found on cervical cancer screening uptake studies with $5.7 \%$ in Nnewi ${ }^{[11]}, 1.78 \%$ in Owerri $^{[12]}, 8.7 \%$ in Ogun state ${ }^{[13]}$, all in Nigeria and $8.5 \%$ in a study carried out in Ghana. ${ }^{[14]}$ Utilization of cervical cancer screening services for the index study is lower than $20 \%$ reported among female sex workers in some selected brothels in Abuja, Nigeria. ${ }^{[9]}$ It is also lower than $21 \%$ found a Tanzanian study ${ }^{[15]}$ and $17.5 \%$ at a study in Kenya. ${ }^{[16]}$ It was rather higher than what was reported in Mozambique where none of the study participants had been screened for cervical cancer. ${ }^{[17]}$ Some of their reasons for low utilization of cervical cancer screening services in the present study include non-availability of the screening services at the health facility, attitude of health workers in effecting utilization, cost of the screening test and time spent at health facility; but majority do not have clear reasons for non-utilization of cervical cancer screening services. In the study by Ilesanmi and Kehinde ${ }^{[9]}$, majority gave no particular reason, but procrastination and lack of accessibility were contributory reasons.

Significant demographic characteristics found to be associated with utilization of cervical cancer screening services in this study include age, marital status, education, number of children, and 
income level. More of younger women utilized the screening services than the older ones. Similarly, according to Kileo ${ }^{[15]}$, increasing age was associated with a decreased use of screening services with younger women being more likely to be screened than older women. On the other hand, a study in Kenya found that women screened for cervical cancer were generally older than those not screened. [16] The divorced and the widowed were behind in the utilization of the services. The current study result is in agreement with an Indian study where marital status was a significant factor of utilization ${ }^{[18]}$ but both studies differ in such a way that quite unlike the present study, married, divorced and widowed were more likely to utilize the cervical cancer screening services than single women. The study contradicts the findings in Kileo ${ }^{[15]}$ which did not find marital status as an associated factor for utilization of cervical cancer screening services. Education showed inverse relationship with utilization of cervical cancer screening services in the study area. Those who utilized the services were more of traders and those without children. Only the income earners of more than $\$ 60,000$ (144 USD) monthly utilized the cervical cancer screening services. On the contrary, one study ${ }^{[19]}$ found that women with higher income levels were less likely to participate in the visual inspection-based screening. In another study by Gharoro and Ikeanyi ${ }^{[20]}$, women with higher education level were more likely to participate in screening since women are less likely to be screened when they do not understand what is being asked of them.

\section{CONCLUSION}

The study revealed that majority 380 $(95.2 \%)$ of the respondents have never utilized cervical cancer screening services whereas only $19(4.8 \%)$ utilized. That is to say that utilization of cervical cancer screening among women in Ikwerre, Southern Nigeria is very low. Some reasons given for non-utilization included women availability at the health facility, the cost of screening, and time spent at the facility. Thus, the availability at the health facility and the cost of screening were seen to affect the utilization of cervical cancer screening services by women. There is need to encourage women to utilize the cervical cancer screening services through awareness campaigns by Government at Federal, State and Local levels. Medical Professionals have a major role to play in this regard. The government should intensify effort to ensure the cost of the screening service is made affordable in the society.

\section{Acknowledgement: None}

\section{Conflict of Interest: None}

\section{Source of Funding: None}

\section{Ethical Approval: Approved}

\section{REFERENCES}

1. World Health Organization. Comprehensive cervical cancer control: A guide to essential practice. Second edition. 2015.

2. Airede LR, Onakewhor JUE, Aziken ME, Ande ABA, Aligbe JU. Carcinoma of the Uterine Cervix in Nigerian Women: The Need to Adopt a National Prevention Strategy. Sahel Med J. 2010; 11(1): 1-11.

3. GLOBOCAN. Latest world cancer statistics. 2012; Available at http://globocan.iarc.fr/ [Retrieved 20 ${ }^{\text {th }}$ January, 2020].

4. Durowade KA. Prevalence and risk factors of cervical cancer among women in an urban community of Kwara State, North Central Nigeria. J Prev Med Hyg. 2012; 53(4): 213-219.

5. Ijaiya MDA, Jimoh AGA. Knowledge, attitude and practice of cervical smear as a screening procedure for cervical cancer in Ilorin. Nigeria. Trop J Obs Gynaecol, 2010; 21: 114-7.

6. Saslow D, Boetes C, Burke W. American Cancer Society; guidelines for early detection of cancer. Cancer J Clin. 2008; 18(7): 58-72.

7. Federal Ministry of Health. Nigeria Cancer Control Plan 2008-2013, FMOH, Abuja, Nigeria. 2008. 
Okachi-Ordu, C. et.al. Association of demographic characteristics and utilization of cervical cancer screening services among women in Ikwerre, Southern Nigeria.

8. Jeal N, Salisbury C. Self-reported experiences of health services among female Street-based prostitutes: A crosssectional survey. Br J Gen Prac. 2004; 54: $515-9$.

9. Ilesanmi RE, Kehinde DR. Pattern of Utilization of Cervical Cancer Screening Services among Female Sex Workers in Some Selected Brothels in Abuja, Nigeria. Asia-Pacific J Oncol Nurs. 2018; 5(4): 415420.

10. Bessler P, Aung M, Jolly P. Factors affecting uptake of cervical cancer screening among clinic attendees in Trelawny, Jamaica. J Moffitt Cancer Cen. 2007; 14(4): 396-404.

11. Udigwe GO. Knowledge, attitude and practice of cervical cancer screening (Pap smear) among female nurses in Nnewi, South Eastern Nigeria. Niger J Clin Pract. 2006; 9: 40-3.

12. Ezem BU. Awareness and uptake of cervical cancer screening in Owerri, SouthEastern Nigeria. Annals Afr Med. 2007; 6(3): 94-98.

13. Adefuye PO. Knowledge and practice of cervical cancer screening among female professional health workers in a sub-urban district of Nigeria. Nig Med Pract. 2006; 50 : 19-22.

14. Adanu RMK. Cervical cancer knowledge and screening in Accra, Ghana. J. Women's Health and Gen Med. 2002; 11: 487.

15. Kileo NM, Michael D, Neke NM, Moshiro C. Utilization of cervical cancer screening services and its associated factors among primary school teachers in Ilala Municipality, Dar es Salaam, Tanzania. BMC Health Serv Res. 2015; 15: 546-552.

16. Morema EN, Atieli HE, Onyango RO, Omondi JH, Ouma C. Determinants of cervical screening services uptake among 18-49 year old women seeking services at the Jaramogi Oginga Odinga Teaching and Referral Hospital, Kisumu, Kenya.,". BMC Health Serv Res. 2014; 14: 330-5.

17. Lafort Y, Lessitala F, Candrinho B, Greener L, Greener R, Beksinska M, Smit JA, Chersich M, Delva W. Barriers to HIV and sexual and reproductive health care for female sex workers in Tete, Mozambique: results from a cross-sectional survey and focus group discussions. BMC Pub Health. 2016; 20(16): 601-8.

18. Nene B, Jayant K, Arrossi S, Shastri S, Budukh A, Hingmire S, Sankaranarayanan R. Determinants of women s participation in cervical cancer screening trial, Maharashtra, India. Bull World Health Org. 2007; 85(4): 264-272.

19. Kritpetcharat O, Suwanrungruang K, Sriamporn S, Kamsa-Ard S, Kritpetcharat P, Pengsaa $P$. The coverage of cervical cancer screening in KhonKaen, Northeast Thailand. Asian Pac J Cancer Prev. 2003; 4(2): 103-6.

20. Gharoro E, Ikeanyi E. An appraisal of the level of awareness and utilization of the Pap smear as a cervical cancer screening test among female health workers in a tertiary health institution. Int $\mathbf{J}$ Gynecol Cancer. 2006; 16(3): 1063-8.

How to cite this article: Okachi-Ordu, C., Nworuh, O.B., Nwaokoro, J.C. et.al. Association of demographic characteristics and utilization of cervical cancer screening services among women in Ikwerre, Southern Nigeria. International Journal of Research and Review. 2022; 9(2): 419-424. DOI: https://doi.org/ 10.52403/ijrr.20220253 